\title{
Incidental findings in pretreatment and post- treatment orthodontic panoramic radiographs
}

\begin{abstract}
Panoramic radiographs are the most requested imaging exams in dentistry and an essential part of the documentation used by orthodontists in treatment planning. Alterations that modify bone density and the trabecular bone pattern can be finding in panoramic radiographs before and after the orthodontic treatment. Furthermore, the transition between the mixed to the permanent dentition is a complex process that can incur in fails and odontogenic anomalies. The identification of incidental findings that may demand specific dental or medical treatment is important to provide satisfactory dental care. Material and methods: The aim of this study was to evaluate panoramic radiographs obtained before and after the orthodontic treatment in order to identify the most prevalent incidental findings. Five hundred panoramic radiographs (250 pretreatment and 250 post-treatment) from patients between eleven and eighteenyears-old obtained between 2005 and 2015 were selected from the archives of the Department of Orthodontics, Bauru School of Dentistry, and University of São Paulo. The image analysis was performed by one single examiner. Results: The incidence of impacted teeth and supernumerary teeth was significant higher in the pretreatment group $(\mathrm{p}<0.05)$. The incidence of root dilacerations, osteosclerosis and the presence of orthodontic retainers was significant higher in the post-treatment group $(\mathrm{p}<0.05)$. Apical remodeling in the incisors was observed in 180 patients in the post-treatment group. Conclusion: In conclusion, clinical relevant incidental findings were observed in both groups. Special care should be taken while evaluating post-treatment radiographs to diagnosis alterations that may require intervention or interfere in other dental treatments.
\end{abstract}

Keywords: dental radiology, incidental findings, orthodontics

\author{
Volume 5 Issue I - 2018
}

\author{
Wilson Gustavo Cral, Mariana Quirino \\ Silveira, Izabel Regina Fischer Rubira-Bullen, \\ Ana Lúcia Alvares Capelozza \\ Department of Stomatology, University of São Paulo, Bauru, \\ Brazil
}

Correspondence: Wilson Gustavo Cral, Department of Stomatology, Bauru School of Dentistry, University of São Paulo, Al. Octávio Pinheiro Brisola, Cidade Universitária, 9-75, Zip Code- 17012-90, Bauru- São Paulo, Brazil,Tel +55 (14) 32358000, Email wgcral@gmail.com

Received: January 22, 2018 | Published: February 12, 2018

\section{Introduction}

Panoramic radiographs provide proper information for most oral surgery procedures panning, for the evaluation of orthodontic treatments progress, for growth and development of children follow up and for oral health surveys in specific populations. Furthermore, the panoramic imaging allows the complete visualization of dental and bone anatomic landmarks and structure in the maxilla and mandible. ${ }^{1}$ Panoramic radiographs associated with clinical examination are used in orthodontic diagnosis and treatment plan. These radiographs are essential to evaluate teeth eruption, and are an instrument for the detection of pathologies in the jaws. ${ }^{2}$

During the panoramic radiography imaging interpretation, there is the possibility for the dentist to identify radiographic findings unrelated to the main reason of the imaging examination or to the patient's complaint. The incidental findings on panoramic radiographs for orthodontic purposes are of special interest to the clinician. In many cases these findings may indicate pathologies that require other dental or medical interventions or can modify the initial treatment plan. $^{2}$

Eight per cent of the orthodontic patients are at age of transition between the mixed to the permanent dentition, a period in which dental anomalies findings are frequent. Bondemark, (2006) analyzed 496 pretreatment panoramic radiographs from orthodontic patients. Incidental findings were reported in 43 patients. Osteosclerosis, apical endodontic lesion, dentigerous cyst, odontoma, tooth morphologic alterations and alveolar bone reabsorption were observed. ${ }^{2}$ The data regarding the prevalence of incidental findings in post-treatment follow up radiographs is scarce.

The aim of this study was to investigate the type and frequency of incidental findings in the maxillofacial region of panoramic radiographs obtained for orthodontic treatment purposes. Images obtained before and after orthodontic treatment were evaluated and the incidence of the findings in both groups was compared.

\section{Materials and methods}

This study was approved by the Ethics Committee of the Bauru School of Dentistry (protocol n. 970,779). Panoramic radiographs from patients treated with fixed orthodontic appliances from 2005 to 2015 were selected from the archives of the Department of Orthodontics, Bauru School of Dentistry, University of São Paulo. The samples were selected giving priority to the most recent records in order to obtain panoramic radiographs of higher quality. Two hundred and fifty dental records of patients with complete orthodontic documentation, pre- and post-orthodontic treatment were selected. A total of five hundred panoramic radiographs were analyzed.

Inclusion criteria for selection were complete radiographic documentation; patients aged 11-18years that underwent treatment with fixed orthodontic appliances; exams that have good quality in the image. Cases with incomplete radiographic documentation, presence of artifacts in the region to be examined were excluded.

After selection, the panoramic radiographs were divided in two groups with 250 images: Group A: pretreatment; Group B: post- 
treatment. When necessary radiographic images taken between the beginning and end of treatment (panoramic or periapical) were used to confirm or exclude a diagnostic hypothesis. Previous to the radiograph analysis, a group of images randomly selected were interpreted both for the examiner and one experienced radiologist in order to have agreement in the diagnosis. For the main image analysis was performed by one single examiner.

Dental Agenesis was considered only when the primary tooth was present and the germ/permanent tooth was absent in the panoramic radiograph; Enamel Pearls were identified using the panoramic radiograph and, when available, periapicals. The criteria for diagnosis of impacted tooth were: lack of space in the dental arch, abnormal position of the tooth germ, presence of obstacles in the eruption path. The external root resorption finding was considered for posterior teeth. Orthodontic containments, plates and screws were classified as present (1) or absent (0). Orthodontic apical root remodeling: Diagnosed as the roundness of the root apex specially in the anterior teeth and classified as present (1) or absent (0).
After one month, $10 \%$ of the total sample was randomly selected and analyzed again to perform the intra-examiner agreement text. The images were interpreted with the aid of a light box in a room with proper lighting. The Kapa test was performed to evaluate the intraobserver agreement. The Kappa test showed an agreement of 0.97 . The Wilcoxon test was performed to compare the findings pre and post-treatment, adopting the significance level $\alpha=0.05$. Continuous variables are reported as means \pm standard deviation (SD).

\section{Results and discussion}

From the patients selected, 141 were females and 109 males. The mean age was $14.5 \pm 2.29$. In group A 169 patients were between 11 and 13years-old and 80 between 14 and 17years-old. In group B 26 patients were between 11 and 13year-old, 129 between 14 and 17 years-old and 95 patients were older than 17 years-old.

Some of the incidental findings were present in group A but not $\mathrm{B}$, while others were present in both groups or just in group B. The findings distributions are described in Table $1 \& 2$.

Table I Presence of dental anomalies incidental findings in group A and B. Bold values $=p<0.05$

\begin{tabular}{|c|c|c|c|c|c|c|c|}
\hline \multirow{3}{*}{$\begin{array}{l}\text { Incidental } \\
\text { finding }\end{array}$} & \multicolumn{3}{|l|}{ Group A } & \multicolumn{4}{|l|}{ Group B } \\
\hline & \multirow[t]{2}{*}{$\begin{array}{l}\text { Total number of } \\
\text { findings }\end{array}$} & \multicolumn{2}{|c|}{$\begin{array}{l}\text { Panoramic } \\
\text { radiographs }\end{array}$} & \multirow[t]{2}{*}{$\begin{array}{l}\text { Total number of } \\
\text { findings }\end{array}$} & \multicolumn{2}{|c|}{ Panoramic radiographs } & \multirow[t]{2}{*}{$p$} \\
\hline & & $\mathbf{n}$ & $\%$ & & $\mathbf{n}$ & $\%$ & \\
\hline Dental Agenesis & 24 & 10 & 4 & 22 & 9 & 3.6 & 0.414 \\
\hline Impacted tooth & II & II & 4.4 & 0 & 0 & 0 & 0.001 \\
\hline $\begin{array}{l}\text { Supernumerary } \\
\text { tooth }\end{array}$ & 8 & 5 & 2 & 0 & 0 & 0 & 0.039 \\
\hline Dilacerated root & 54 & 39 & 15.6 & 73 & 48 & 19.2 & 0.049 \\
\hline Hypercementosis & 1 & 1 & 0.4 & 6 & 5 & 2 & 0.059 \\
\hline Microdontia & 1 & 1 & 0.4 & 6 & 3 & 1.2 & 0.102 \\
\hline Enamel pearls & 2 & 2 & 0.8 & 8 & 6 & 2.4 & 0.063 \\
\hline
\end{tabular}

Table 2 Presence of endodontic findings, metallic materials, orthodontic apical root remodeling, osteosclerosis and odontogenic pathologies in group A and B. Bold values $=\mathrm{p}<0.05$

\begin{tabular}{|c|c|c|c|c|c|c|c|}
\hline \multirow{3}{*}{ Incidental finding } & \multicolumn{3}{|l|}{ Group A } & \multicolumn{4}{|l|}{ Group B } \\
\hline & \multirow[t]{2}{*}{$\begin{array}{l}\text { Total number of } \\
\text { findings }\end{array}$} & \multicolumn{2}{|c|}{$\begin{array}{l}\text { Panoramic } \\
\text { radiographs }\end{array}$} & \multirow[t]{2}{*}{$\begin{array}{l}\text { Total number of } \\
\text { findings }\end{array}$} & \multicolumn{2}{|c|}{$\begin{array}{l}\text { Panoramic } \\
\text { radiographs }\end{array}$} & \multirow[t]{2}{*}{$p$} \\
\hline & & $\mathbf{n}$ & $\%$ & & $\mathbf{n}$ & $\%$ & \\
\hline Supernumerary root & 0 & 0 & 0 & 1 & 1 & 0.4 & 0.317 \\
\hline Apical endodontic lesion & I & 1 & 0.4 & 4 & 4 & 1.6 & 0.18 \\
\hline Dental pulp stones & 4 & 4 & 1.6 & 9 & 7 & 2.8 & 0.096 \\
\hline $\begin{array}{l}\text { Root reabsorption (internal/ } \\
\text { external) }\end{array}$ & 4 & 3 & 1.2 & 9 & 6 & 2.4 & 0.187 \\
\hline Orthodontic containments & 0 & 0 & 0 & 211 & 211 & 84.4 & 0 \\
\hline Dental implant & 0 & 0 & 0 & 3 & 2 & 0.8 & 0.18 \\
\hline Plates and screws & I & 1 & 0.4 & 2 & 2 & 0.8 & 0.317 \\
\hline $\begin{array}{l}\text { Orthodontic apical root } \\
\text { remodeling }\end{array}$ & 0 & 0 & 0 & 180 & 180 & 72 & 0 \\
\hline Osteosclerosis & 20 & 19 & 7.6 & 31 & 30 & 12 & 0.048 \\
\hline Dentigerous cyst & I & I & 0.4 & 0 & 0 & 0 & 0.317 \\
\hline Composite odontoma & I & I & 0.4 & 0 & 0 & 0 & 0.317 \\
\hline
\end{tabular}


Panoramic radiography allows evaluating lesions in the jaws, the relationship of the teeth to each other, the number and location of intraosseous teeth, among other alterations. Easy access to the examination and the radiation doses four to six times lower, when compared with full-mouth series of periapical projections, are advantages of this method. The aim of this study was to evaluate the presence of radiographic findings, with clinical implications in panoramic radiographs performed at the beginning and end of orthodontic treatment. Several of the alterations observed were possibly found only in view of this opportunity to obtain a panoramic radiograph, which may be considered as incidental findings. The highest prevalence of the findings occurred in the post-orthodontic treatment radiographs, highlighting the clinical importance that the orthodontic apical remodeling plays during the evolution of orthodontic treatment, even representing an indication of clinical success. $^{3}$

The increase of osteosclerosis lesions was observed in the posttreatment group, rising the questioning regarding its relation with the orthodontic movement. It is known that the cause of osteosclerosis is idiopathic. The information regarding the role of the orthodontic movement on its etiology is still controversial and scarce in the literature. The bone that composes these areas of osteosclerosis has normal structure and functioning, and the difference lies in its greater trabecular density. Therefore, it is possible to move teeth, apply miniimplants and osseointegrated implants in these areas, as long as these radiopaque images are not related to teeth without pulp vitality. The idea is to use forces of lesser intensity than those conventionally applied. The decrease in force corresponds to a compensation, since, due to the higher local bone density, bone deflection does not occur. Thus, there will be a normal movement, even in the densest area., However, bone remodeling may take longer because bone trabeculae are thicker and the medullary spaces are reduced. ${ }^{5}$

Pretreatment radiographic examination allows the identification of possible alterations that may influence the orthodontic treatment planning. Among these alterations one can mention conditions with need for restorative, endodontic, periodontal or surgical treatments; diagnosis of dental agenesis; supernumerary teeth; root resorption, which may definitively require previous intervention. Additionally, the evaluation after the orthodontic treatment allows a comparison with the initial condition and the identification of the alterations that arose as a result of the orthodontic interference and its respective clinical implication. Thus, in this study we evaluated radiographs taken before and after treatment

In this study, $56.4 \%$ of the patients were female and $43.6 \%$ were male. Most patients start orthodontic treatment between 11 and 13years $(67.9 \%)$, and they finish between 14 and 16years (51.6\%). Granlund (2012) investigated a similar population. The authors evaluated 1278 panoramic radiographs from young patients $(530$ males and 757 females) with mean age of 14years-old. The presence of incidental findings in the patients with mixed dentition (i.e. supernumerary teeth) was reported. ${ }^{6}$

In this research there was a significant reduction of supernumerary teeth and impacted teeth in the post-treatment radiographs. If the supernumerary teeth are partially or totally erupted, they may cause retention of dental biofilm, influence periodontal health and dental alignment. Supernumerary teeth may also interfere in the occlusion and should be extracted whenever they could impair the development of adjacent teeth. ${ }^{7,8}$ Impacted teeth also have an indication of extraction for the prevention of dental ankyloses and root resorption due to the proximity between the roots. The possibility of cystic or neoplastic transformation of the remaining dental follicle should also be considered. ${ }^{8}$

Other dental anomalies, such as enamel pearl, root laceration, supernumerary root, microdontia and hypercementose were more numerous after orthodontic treatment. However, studies that related their occurrence with orthodontic treatment are not available. The supernumerary root does not require treatment, however, its identification is important for the planning of dental procedures. ${ }^{9}$ Regarding the higher number of root dilacerations in the post-treatment radiographs, it is possible that this result is related to the complete formation of the roots, which can be observed in higher numbers at the end of orthodontic treatment. The presence of hypercementosis may hamper orthodontic movement and cause clinical and technical peculiarities, such as the need to apply maneuvers for bracket angulation. The presence of hypercementosis does not appear to be strictly aggravating during orthodontics, but requires that the clinician be aware of the evolution of each specific case. ${ }^{10}$

In this study, 4 images compatible with external radicular resorption were observed in 3 patients $(1.2 \%)$ in the pre-treatment group and 9 images in 6 patients $(2.4 \%)$ in the post treatment group. External root resorption and its progression may be related to orthodontic treatment. The main related factors to be considered are: duration, intensity, application method and direction of the force movement; As well as genetics; Systemic diseases; Root morphology and local traumas. During induced tooth movement, the applied force can compress the periodontal ligament and, consequently, cause the death of cementoblasts, causing the osteoblasts to occupy the root surface, thus initiating the dental resorption associated with orthodontic movement. ${ }^{11}$ Han (2005) stated that tooth intrusion causes four times more root resorption than extrusion. Levander (1998) stated that root resorption is significantly higher in patients submitted to continuous orthodontic movement compared to the ones whose orthodontics is performed with pauses, which allows cement recovering. The treatment of external root resorptions in patients undergoing orthodontic treatment it is based on the principle that removal of the cause interrupts the process. The inflammatory dental resorption ceases after a week of disruption of the forces applied to the tooth. ${ }^{12}$ However, chronic lesions are able to promote erosions in the cementum and the root apex region, causing a necrotic material retention preventing the reparative process. In such cases endodontic treatment is suitable. . $^{13,14}$

Unless not statistical significantly, in the post-treatment group a higher incidence of dental pulp stones was observed. Over time, the dental pulp undergoes physiological changes due to its aging. With the influence of other factors such as caries, periodontal disease and traumatisms, the deposition of mineralized tissue in the form of nodules in the interior of the pulp cavity may occur. The relation between the presence of pulp nodules and orthodontic movement was reported, however, most authors believe that its occurrence is associated with the predisposition of factors resulting from the pulp physiological aging process. ${ }^{15-17}$

One image that suggests a dentigerous cyst and one odontoma were observed in the sample investigated. Carvalho (2010) reported that $42.2 \%$ of the dentigerous cysts were present in images of patients between 11 and 20years-old. This age ranges close to the age of the patients included in this study. ${ }^{18}$ The dentigerous cyst can inhibit the 
eruption of the tooth involved. ${ }^{19}$ In the case observed in the sample, the involved tooth was extracted and the lesion treated before orthodontic treatment began. Among the benign tumors of the mouth, odontoma is the most common. It develops in patients younger than 20yearsold, during the odontogenesis process. ${ }^{20,21}$ Composite odontoma has lower growth potential than the complex. Usually, odontoma is associated with permanent non-erupted teeth and is the most common odontogenic tumors associated with delays in tooth eruption. In such cases of treatment with surgical removal is important. ${ }^{20,22}$ Is important to highlight that these lesions should be submitted for histopathological examination for diagnosis.

Metalic devices, such as dental implants and orthodontic containments, were observed in the post-treatment group. Orthodontic restraint is part of post-treatment in order to prevent crowding recurrence, especially in lower incisors. Dental implants can be part of rehabilitating treatments, however treatment costs, cultural differences, comfort, age and service accessibility need to be considered..$^{23}$ The use of plates and screws in orthognathic surgery respects a treatment sequence, since orthodontic diagnosis and planning are fundamental for the isolated or joint correction of the skeletal discrepancies of the jaws. ${ }^{24,25}$

The orthodontic apical remodeling was observed in 180 charts in the posttreatment images, which is clinical relevant information. The forces of tooth movement provoke the activation of osteoclasts through the modulation pathway of inflammation that, after exceeding a certain threshold, cause the replacement of cells of the periodontal ligament by osteoblasts, initiating a process of root resorption, also called orthodontic apical remodeling ${ }^{3}$, in this study observed mainly in the anterior region. There are studies that investigate which genetic factors play an important role in their occurrence. In particular, if there is an increase in interleukin-1 (IL-1) alpha and beta, a chemical mediator involved in the processes of bone and tooth resorption found in periodontal tissues. ${ }^{26} \mathrm{Al}$-Qawasmi ${ }^{26}$ reported that the polymorphism in the IL-1 beta gene was responsible for $15 \%$ of the total variation of the orthodontic apical remodeling in the upper central incisors, and the other dental groups did not present a statistically significant association.

This article reports a retrospective investigation performed only with the information obtained in the radiographic examinations. Other information that could improve the diagnosis has not been investigated. In addition, panoramic x-ray may show $15-25 \%$ image distortion. Although aware of these limitations, this research obtained an important epidemiological data, which may alert the professionals to the clinical and radiographic control of patients during and after orthodontic treatment. Future studies that could accompany all stages of orthodontic treatment, from clinical examination, radiographic imaging, treatments, and could explore the relationship between clinical and radiographic diagnosis, should be encouraged.

\section{Conclusion}

In this study it was possible to observe in the pre-treatment radiographs the presence of important findings for the diagnosis and planning of orthodontic treatment. Some of them requiring specific treatments, such as: dentigerous cyst and composite odontoma, in addition to retained and supernumerary teeth. The greatest number of incidental findings was present in the radiographs taken after orthodontic treatment. The apical orthodontic remodeling was present in the majority of the patients and requires clinical and radiographic follow-up. The comparison between these two moments is extremely important because certain alterations may have their etiologies related or not to orthodontic therapy. The clinician should pay special attention to incidental findings while following-up of each patient.

\section{Acknowledgements}

None.

\section{Conflict of interest}

I declare that there are no conflicts of interest between the authors of the article entitled "Incidental findings on pre-treatment and posttreatment orthodontic panoramic radiographs".

\section{References}

1. Vicci JC, Capelozza ALA. Incidência de lesões dentárias e ósseas evidenciadas através de radiografia panorâmica. Rev Unime. 2002;14(2):43-46.

2. Bondemark L, Jeppsson M, Lindh-Ingildsen L, et al. Incidental findings of pathology and abnormality in pretreatment orthodontic panoramic radiographs. Angle Orthod. 2006;76(1):98-102.

3. Hartsfield JK. Pathways in external apical root resorption associated with orthodontia. Orthod Craniofac Res. 2009;12(3):236-242.

4. Khurana NA, Khurana G, Uppal N. Socket sclerosis: a rare complication obstructing orthodontic tooth movement. Orthodontics (Chic.). $2011 ; 12(2): 1-5$.

5. Consolaro A. Reabsorções Dentárias nas especialidades clínicas. 3rd ed. Maringá: Dental Press; 2012.

6. Granlund CM, Lith A, Molander B, et al. Frequency of errors and pathology in panoramic images of young orthodontic patients. Eur J Ortho. 2012;34(4):452-457.

7. Correa FG, Ferreira FV, Friedrich LR, et al. Prevalence of supranumerary teeth - retrospective study. Int J Dent. 2009;8(1):11-15.

8. Loreto AFV, Kermer F, Oliveira RV. Supernumerary in the region of jaw interfering in occlusion: Diagnosis, and treatment planning of a case. Rev Uningá. 2015;21(1):27-31.

9. Khojastehpour L, Khayat A. Maxillary Central Incisor with Two Roots: a Case Report. J Dent Tehran Univ Med Scien. 2005;2:74-77.

10. Humerfelt A, Reitan K. Effect hipercementosis on the movability of teeth during orthodontic treatment. Angle Orthod. 1996;36(3):179-189.

11. Kurol J, Owman-Moll P. Hyalinization and root resorption during early orthodontic tooth movement in adolescents. Angle Orthodontist. 1998;68:161-165.

12. Levander E, Bajka R, Malmgren O. Early radiographic diagnosis of apical root resorption during orthodontic treatment: a study maxillary incisors. Eur J Orthod. 1998;20(1):57-63.

13. Deardorf KA, Swartz ML, Newton CW, et al. Effect of root canal treatments on dentin permeability. J Endod. 1994;20(1):1-5.

14. Smidt A, Nuni E, Keinan D. Invasive Cervical Root Resorption: Treatment Rationale with an Interdisciplinary Approach. JOE. 2007;33:1383-1387.

15. Consolaro A. Radiografias periapicais prévias ao tratamento ortodôntico. Rev Dental Press Ortod Ortop Facial. 2007;12(4):14-16.

16. Nixon CE, Saviano JA, King GJ, et al. Histomorphometric study of dental pulp during orthodontic tooth movement. J Endod. 1993;19(1):13-16.

17. Fachin EVF, Luisi SB, Borba MG. The process of pulpal calcification. Rev ABO Nac. 2002;9(6):347-351. 
18. Carvalho RWF, Avelar RL, Araújo FAC, et al. Dentigerous Cyst: An Epidemiologic Study of 192 Cases. Pesq Bras Odontoped Clin Integr 2011;11(3):335-339.

19. Spini RG, Bordino L, Cruz D, et al. Dentigerous cyst: a case report. Arch Argent Pediatr. 2016;114(5):338-342.

20. Girish G, Bavle RM, Singh MK, et al. Compound composite odontoma. J Oral Maxillofac Pathol. 2016;20(1):162.

21. Gyulai-Gaál S, Takács D, Szabó G, et al. Mixed odontogenic tumors in children and adolescents. Fogorc Sz. 2007;100(2):65-69.

22. Slootweg PJ. An analysis of the interrelationship of the mixed odontogenic tumors-ameloblastic fibroma, ameloblástico fibro-odontoma, and odontomas. Oral Surg Oral Med Oral Pathol. 1981;51(3):266-276.
23. Budtz-Jorgensen E, Chung JP, Mojon P. Sucessful aging-the case for prosthetic therapy. J public Health Dent. 2000;60(4):308-312.

24. Araujo AM, Araujo MM, Araujo A. Orthognathic Surgery-Complication or Solution? A Manual for Surgical-Orthodontic Treatment. Dental Press Orthop Facial. 2000;5(5):105-122.

25. Sant'ana E, Jansom M. Orthodontics and Orthognathic Surgeryfrom Planning to Finishing. $R$ Dental Press Ortodon Orthop Facial. 2003;8(3):119-129.

26. Al-Qawasmi RA, Hartsfield JK, Everett ET, et al. Genetic predisposition to external apical root resorption. Am J Orthod Dentofacial Orthop. $2003 ; 123(3): 242-252$. 